\title{
The Facial Profile in the Context of Facial Aesthetics
}

\author{
Werner J. Heppt, $\mathrm{MD}^{1}$ Julia Vent, $\mathrm{PhD}^{2}$ \\ 1 Department of Oto-Rhino-Laryngology, Head and Neck Surgery, \\ Facial Plastic Surgery, Klinikum Karlsruhe, Karlsruhe, Germany \\ 2 Department of Oto-Rhino-Laryngology, Head and Neck Surgery, Ruprecht- \\ Karls-University of Heidelberg, Universitätsmedizin Mannheim (UMM), \\ Mannheim, Germany

\begin{abstract}
Address for correspondence Werner J. Heppt, MD, Department of Oto-Rhino-Laryngology, Head and Neck Surgery, Facial Plastic Surgery, Klinikum Karlsruhe, Moltkestraße 90, 76133 Karlsruhe, Germany (e-mail: wheppt@web.de).
\end{abstract}

Facial Plast Surg 2015;31:421-430.
Abstract
Keywords
- facial profile
- history
- evolvement of a beauty concept
- ethnics

Beauty has been an intriguing issue since the evolving of a culture in mankind. Even the Neanderthals are believed to have applied makeover to enhance facial structures and thus underline beauty. The determinants of beauty and aesthetics have been defined by artists and scientists alike. This article will give an overview of the evolvement of a beauty concept and the significance of the facial profile. It aims at sharpening the senses of the facial plastic surgeon for analyzing the patient's face, consulting the patient on feasible options, planning, and conducting surgery in the most individualized way.
There is hardly any other peculiarity of men receiving greater interest than beauty-predominantly the beauty of the face.

It is the beauty of childhood and the burst of beauty from youth to early adolescence that fascinates as much as striving for regular harmonious features. This basic instinct of men, associated with the desire of perfectionism and long-lasting attractiveness, explains the attempts to escape personal deficiencies and to line up with "normal" features. Furthermore, all attitudes are superimposed by psychological influences and personal changes during life, predominantly by the age-related metamorphosis coming up after the age of approximately 27 years in women and 36 years in men, the period reputed to be the most attractive in life. Finally, it has to be taken into account regarding all observations that the desirable facial beauty in different cultures is as versatile as the variety of views over human history is.

This article takes up the millennia-old topic of facial beauty by giving a historical overview on the ideals of beauty and to the norms, striving to provide guidance for the physician dealing with facial plastic surgery patients.

\section{Human Beauty}

The earliest findings of human beautification were found from Neanderthals some 40,000 years ago in Murcia, Spain, where sea shells were found, containing brightly colored pigments believed to have served as makeup to augment or even camouflage facial structures. ${ }^{1-3}$

More is known on the aim for perfection of the human face in ancient Egypt from $\sim 4000$ before the common era (BCE), where the heads of children were wrapped to achieve a higher hind head, and makeover was used in abundance to enhance facial features (coal to line the eyelids, green and blue eye shadow with semiprecious stone pigments, e.g., from lapis lazuli, ochre to brighten cheeks and lips, and henna to dye hair and fingertips). ${ }^{4,5}$

Ancient Egyptians were thought to have elaborated a routine of personal hygiene and beauty, as they regarded beauty as a sign of holiness. In tombs, cosmetic palettes were found buried with the deceased as grave goods which further emphasized the idea that cosmetics were not only used for aesthetic but rather magical and religious purposes. ${ }^{4,5}$

Summing up beauty and aesthetics in mathematical orders, the proportions in art and decoration in ancient Egypt were determined by use of a grid system and a "canon of proportions." Up until the end of the New Kingdom's 26th Dynasty, the ancient Egyptians used a grid that measured 18 units to the hairline, or 19 units to the top of the head and thus aimed at establishing rules of beauty and holiness, which also meant royalty. This grid was applied to create depth and perspectives. It was further used particularly in relation to individual standing, kneeling, or seated figures. ${ }^{6}$
Issue Theme The Facial Profile; Guest Editors, Werner J. Heppt, MD, and Stefan Zachow, PhD
Copyright $\odot 2015$ by Thieme Medical Publishers, Inc., 333 Seventh Avenue, New York, NY 10001, USA. Tel: +1(212) 584-4662. 
Shaping the head is not only found in ancient Egypt but also in other cultures, such as in Omsk/Siberia: Skulls were found there from the 4 th century AD with marks that could be due to artificial deformation of a normal skull. They surmise that the ancient communities deliberately deformed the skulls of their children, by applying forces via a head press, almost from the moment of birth-the purpose of this ritual remains unclear, likely for aesthetical reasons. Also, the medieval Italian ruler family Este is often depicted with a steep profile and high hind head-their characteristic feature of being a member of this powerful dynasty (-Fig. 1).

Marcus Vitruvius Pollio, better known as Vitruv, was a Roman architect and engineer from 100 BCE. Not only did he build war machines for Gaius Julius Caesar, but also important water channels and fountains under Emperor Augustus for Rome from 33 BCE on. His theoretical works include a first version of man's typical and balanced proportions; hence, the model is to date named the "Vitruvian man." He postulated that the center of balance and gravity for men is the umbilicus. The first renowned artist and scientist alike to really establish mathematical rules defining a perfect body and face was Leonardo da Vinci. He further developed the model of the Vitruvian man. ${ }^{7}$

Leonardo da Vinci (1452-1519) divided the face into three thirds: from hairline to the eyebrows, from there to the tip of the nose, and from herewith to the chin and analyzed differences and changes from the youthful to the aging profile.

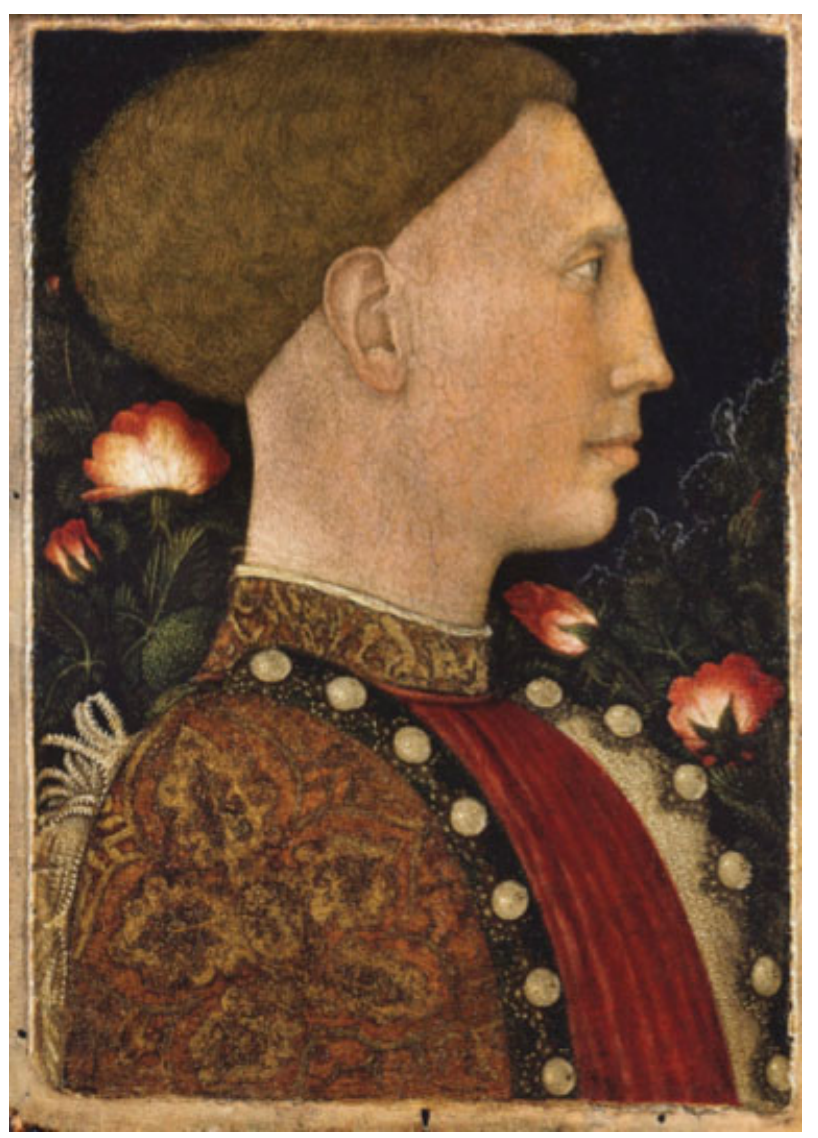

Fig. 1 Leonello d'Este by Pisanello, with kind permission of Zeno.org.
Leonardo was maybe the most fascinating artist and scientist of the Renaissance, some say until today, and defined "divine proportions," which he had studied and refined in the Vitruvian man, creating his own famous version of it, for example, by adding the circle and changing leg and arm positions (-Fig. 2). Leonardo's Vitruvian man now is omnipresent; that is, on the Italian 1-Euro coin, on insurance logos, and more. ${ }^{7}$

Leonardo's works are collected in the so-called Codex Atlanticus-a masterpiece so large that it resembled an atlas, and was thus so named. The Codex Atlanticus is still preserved in the Library Ambrosiana in Milan, Italy. In it, multiple sketches and drawings are composed, trying to express nature in mathematical formulas, since Leonardo was constantly seeking answers to fundamental questions-he also calls for the existence of "10 nasal types": "If you want to acquire facility for bearing in mind the expression of a face, first make yourself familiar with a variety of [forms of] several heads, eyes, noses, mouths, chins and cheeks and necks and shoulders: And to put a case: Noses are of ten types: straight, bulbous, hollow, prominent above or below the middle, aquiline, regular, flat, round or pointed. These hold good as to profile. In full face they are of eleven types; these are equal thick in the middle, thin in the middle, with the tip thick and the root narrow, or narrow at the tip and wide at the root; with the nostrils wide or narrow, high or low, and the openings wide or hidden by the point; and you will find an equal variety in the other details; which things you must draw from nature and fix them in your mind."

In the La Specola Museum in Florence, Italy, there are multiple wax models and drawings of Leonardo da Vinci preserved, showing his unique curiosity as a scientist and artist. It opened in 1775 for the common public and is to date still one of the largest scientific museums in Europe, containing some 3.5 million preserved animals, among which 5,000 are under constant display, and bird skeletons. There are also the largest collections of anatomical wax models visible, of which many have been made or inspired da Vinci himself. ${ }^{8}$

Leonardo da Vinci also illustrated the mathematical masterpiece by Luca Pacioli "De Divina Proportione"-on divine proportion. He underlined his mathematical knowledge by this collaboration, as he himself was not allowed to study at a university as an illegitimate child, and thus acquired his knowledge by merely asking and studying with other artists and scientists.

Jacques Joseph, one of the fathers of modern rhinoplasty, used the da Vinci drawing "Portrait of a Young Woman in Profile" to describe the nasofacial angle, which he called "profile angle.""

Also Michelangelo in the Renaissance times extensively studied the facial profile in his famous pictures of satyrs and characteristic men. Albrecht Dürer (1471-1528) was also interested in the proportions of the human body and especially the facial profile and published 10 sketches of human facial proportions in 1522. His characteristic and expressive facial portrayals are renowned (- Fig. 3).$^{11}$ In the neoclassic times, the German sculptor and artist von Schadow tried to calculate the average measurements of the nose by manually 


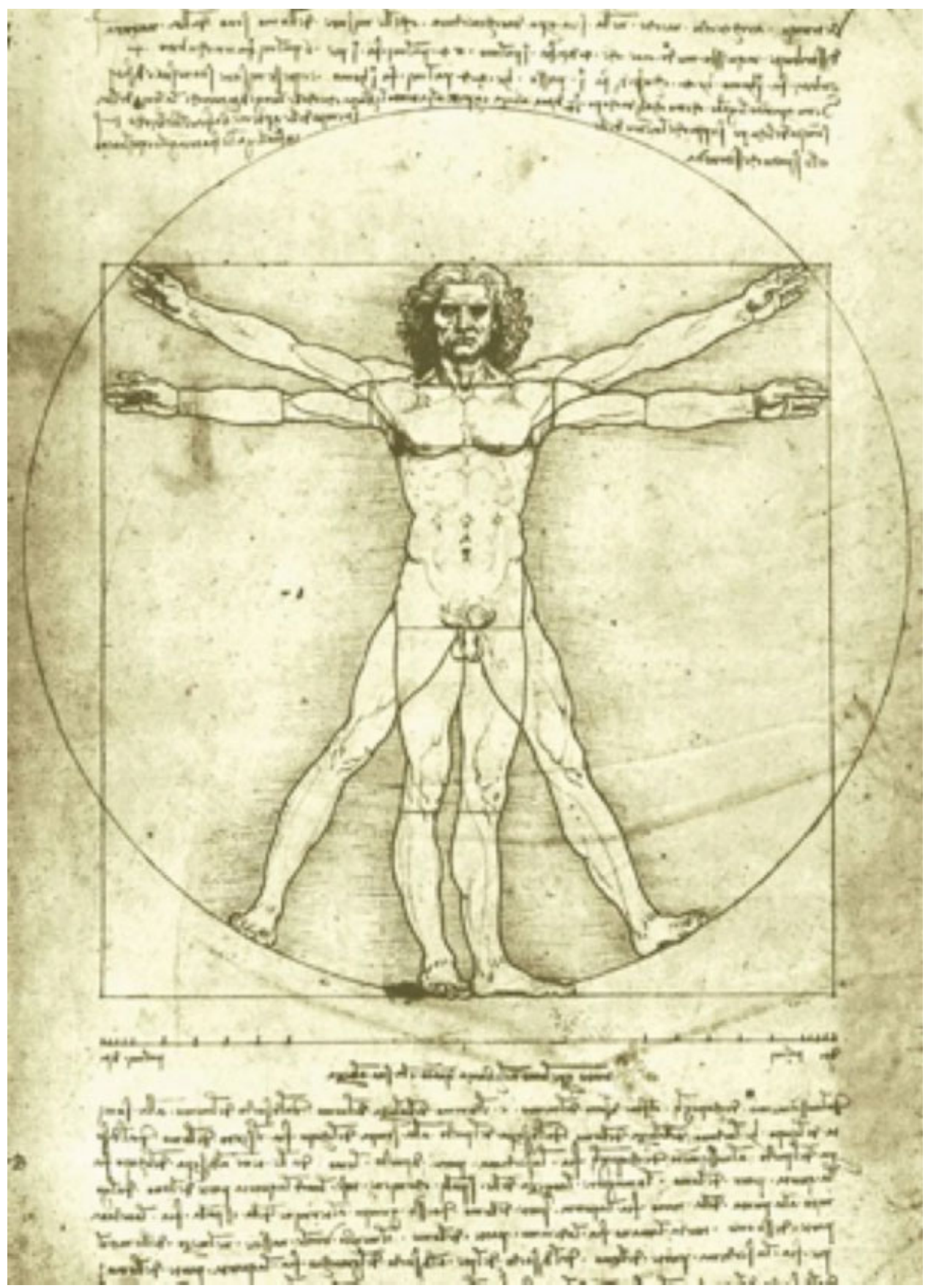

Fig. 2 Leonardo's Vitruvian Man, with kind permission of Zeno.org.

measuring angles of pieces of art-by assuming statues and paintings would depict perfect bodies. ${ }^{10}$

The word aesthetics itself-describing a discipline or virtue-only dates back to a publication of the German philosopher A. G. Baumgarten (1712-1762) in 1750, who created this neologism from the Greek word aiestheticos (sensually perceiving) in a two-book series titled Aesthetica on the topic of perception. Baumgarten and his teacher $\mathrm{Ch}$. Wolff were the founders of this "science of perceiving and defining beauty," and they thus formed the term aesthetics. ${ }^{12,13}$
Long before the term aesthetics was established, though, Saint Thomas Aquinas approached beauty and the sense of perceiving the good theoretically. It comprised not only physical beauty though, but also in a wider sense the beauty of the soul. The first theoretical approach of beauty in a scientific yet philosophical manner was written in the 13th century by him. He postulated that beauty is good and vice versa all good things and actions are beautiful. Pulchra sunt quae visa placent-beautiful is what pleases the sight-he hypothesizes in his work Summa Contra Gentiles, written from 1261 to 1264, and thus gives a first definition of beauty 


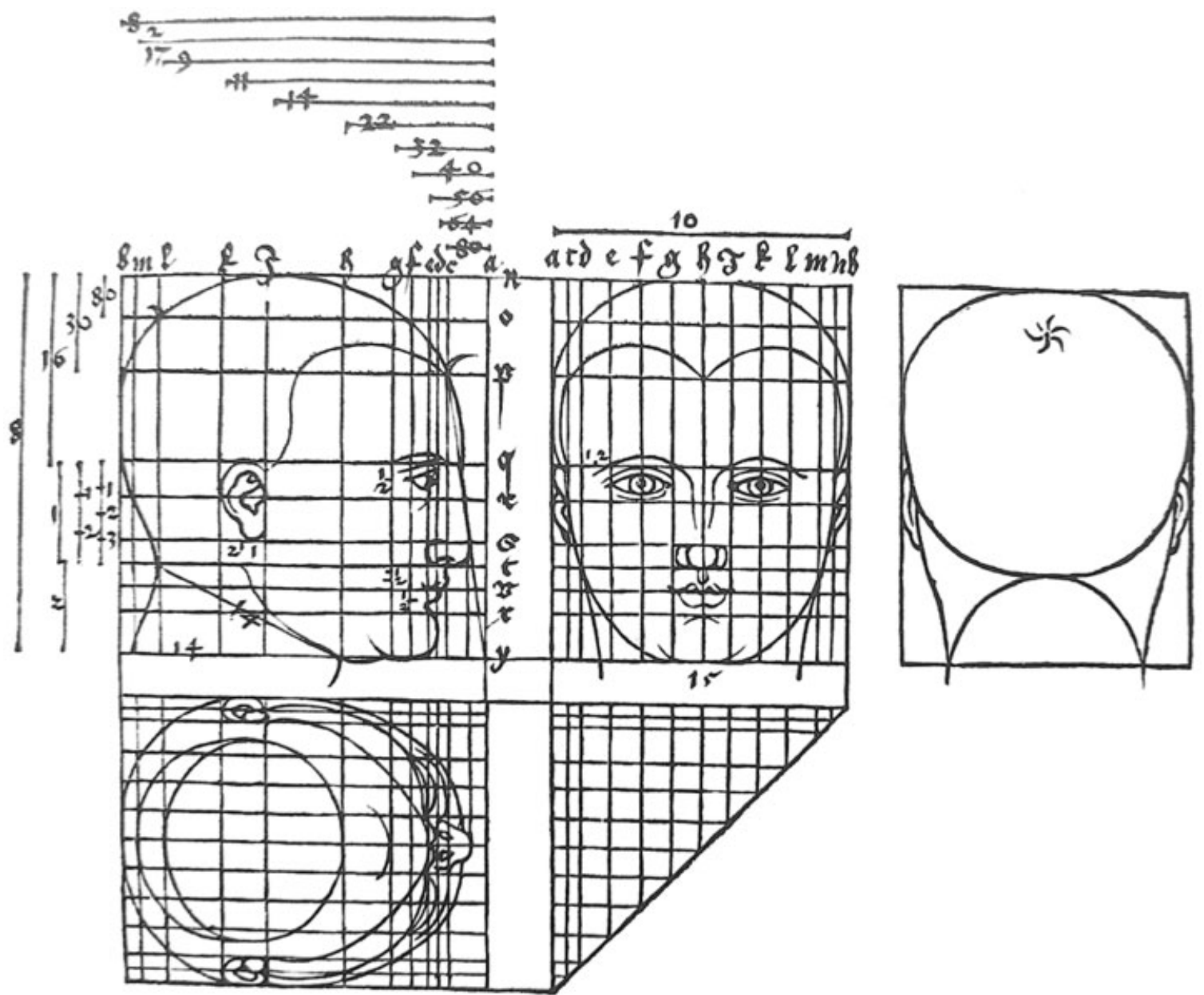

Fig. 3 Facial profile studies of Albrecht Dürer (1471-1528). ${ }^{11}$

in the vestibule of our modern times. Saint Thomas Aquinas postulated three bases as a condition for beauty ${ }^{13}$ :

1. Integritas/perfectio: the uniform perfection

2. Proportio/harmonia: proportion and harmony

3. Claritas/splendor: illumination by god and light

In the later development of art, the facial profile was used to characterize personalities, as in the fairy tale of Pinocchio, the crooked (parrot-beak) nose of witches and even in political satire, as most strikingly performed by the famous artist Honoré Daumier, who painted for newspapers and magazines of the Parisian 19th century, and also created an impressive series of heads of the Court of Justice, where he sculpted enormous noses and profiles to parody the famous and powerful men (-Fig. 4).

These findings are the results of studies over multiple centuries-in science and art alike-which tried to define physiognomy and see special signs in every feature. The antic interpretations of Polemon or Adamantios, the group of authors' names "Pseudo-Aristoteles," tried to assign characteristic traits to special morphisms and body forms, and searched for medieval ages continue those ideas. ${ }^{14}$ Humana Physiognomia, published in 1586 by Giambattista della Porta
(1541-1615), is one of the most famous of these works (-Fig. 5). It influenced the research of Charles Le Brun (1619-1690), who was the second-most influential artist of his time after Louis IV. It marks substantial aspects also of the anthropology of Petrus Camper (1722-1789), a Dutch anatomist; Johann Kaspar Lavater (1741-1801), a Swiss physiognomist; and Louis-Pierre Baltard (1764-1846), a French painter and architect ( - Fig. 6). Comparing human and animal skeleton in detail, some erroneous doctrines emerged at that time, misinterpreting the great variety of skulls of the human family and their relationship to character and intelligence. Representative for those days, Camper postulated that when the brain is large, the face and sensory organs are small arguing that the relationship of the intellect and the face should be directly inverse. ${ }^{15}$

Facial plastic surgery evolved simultaneously to studies of physiognomy, anthropology, and anatomy. In fact, initially it dealt with restoring defects acquired at war or battles, or stigmatizing diseases such as leprosy. The very first description of nasal reconstruction and rhinoplasty were performed by Gaspare Tagliacozzi (1545-1599) at the University of Bologna. He was specialized in reconstructing syphilitic noses and ablations of the nasal cartilage by wounds at war or fight. 


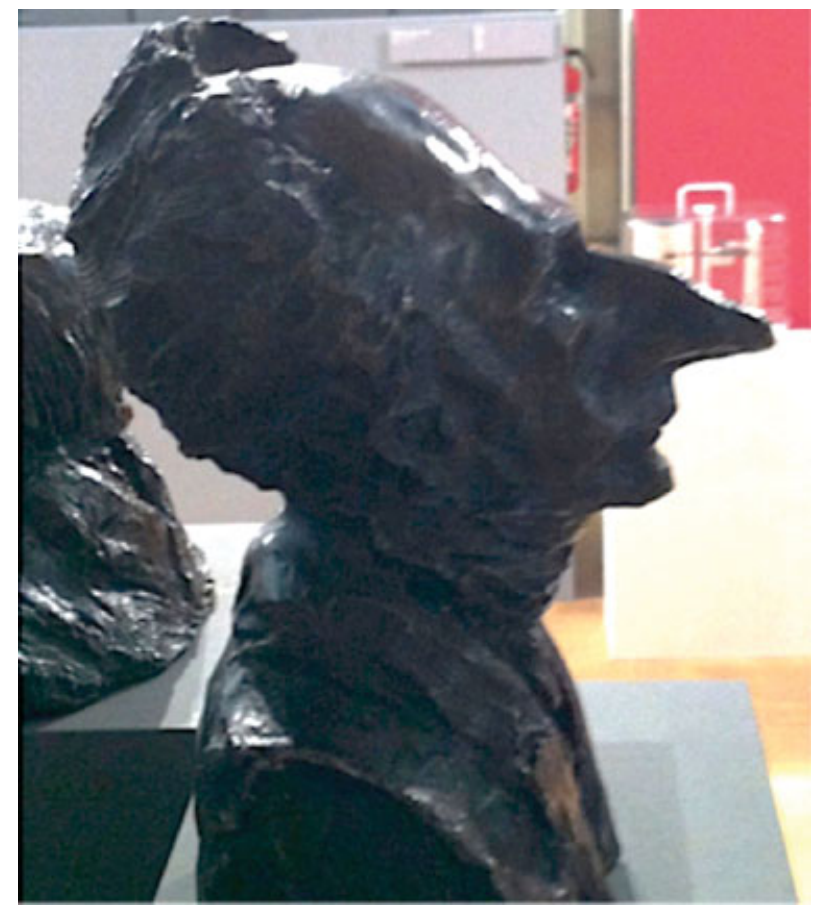

Fig. 4 Busts by Daumier, from the exhibition “Daumier ist ungeheuer” in Berlin, Stiftung Brandenburger Tor, June 2013.

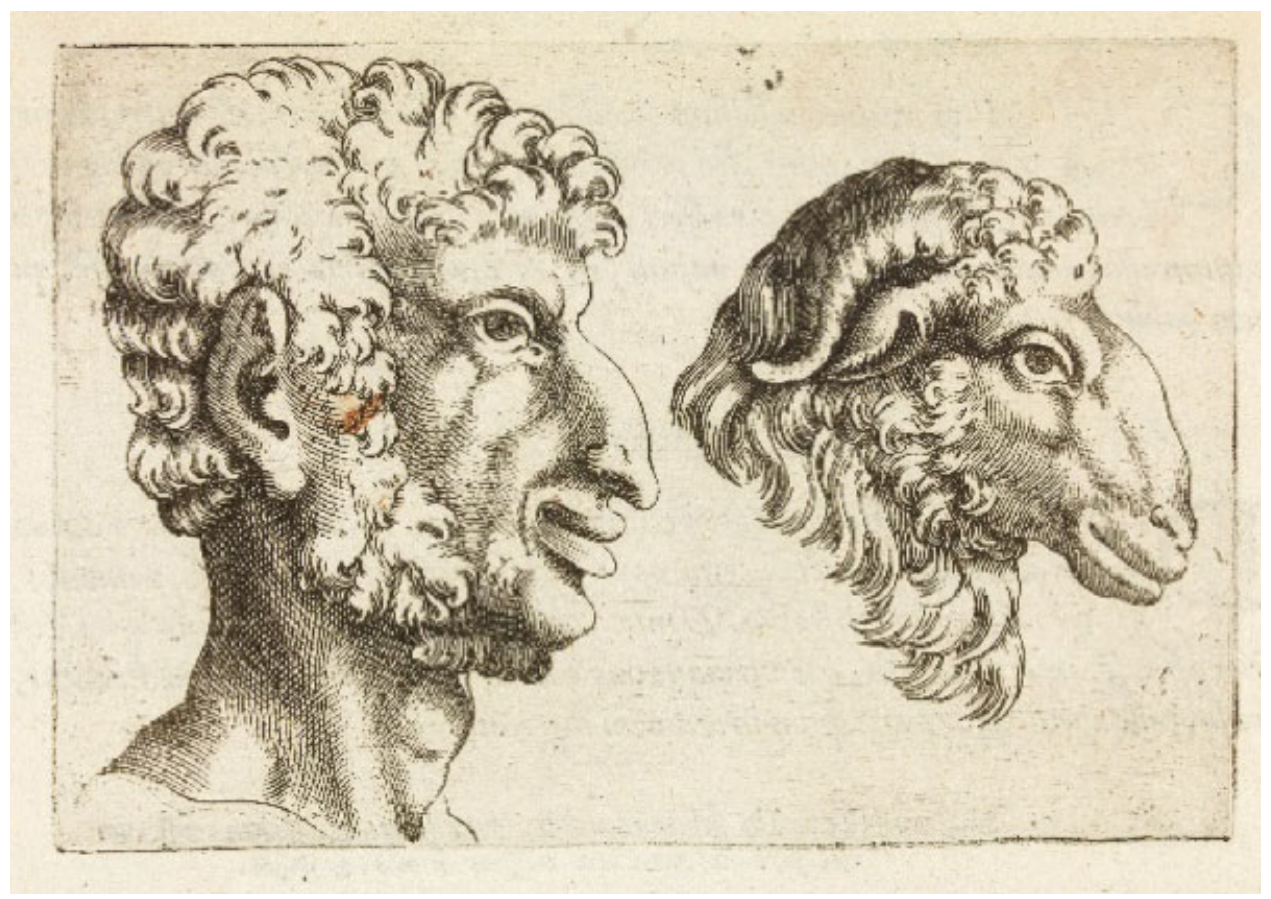

Fig. 5 Giambattista della Porta (1535-1615). Human and sheep. De Humana Physiognomia, $1586{ }^{16}$

Remodeling a facial profile in medical literature was then described by Carl Ferdinand von Graefe (1287-1840) in Berlin who successfully used Tagliacozzi's 200 -year-old description of a forearm flap to reconstruct the nose of a soldier in $1816 .{ }^{10}$

The development of plastic and aesthetic surgery in modern times then started with a description of a rhinoplasty in 1898 in the Berliner Klinische Wochenschrift described by
Jacques Joseph, one of the fathers of modern rhinoplasty. He used the da Vinci drawing "Portrait of a Young Woman in Profile" to describe the nasofacial angle, which he called "profile angle" (-Fig. 7).

In a communication summing up relevant facial angles and formulas on the background of ancient Greek, Roman, and medieval art, Farhad and Naini analyzed the nasal tip 


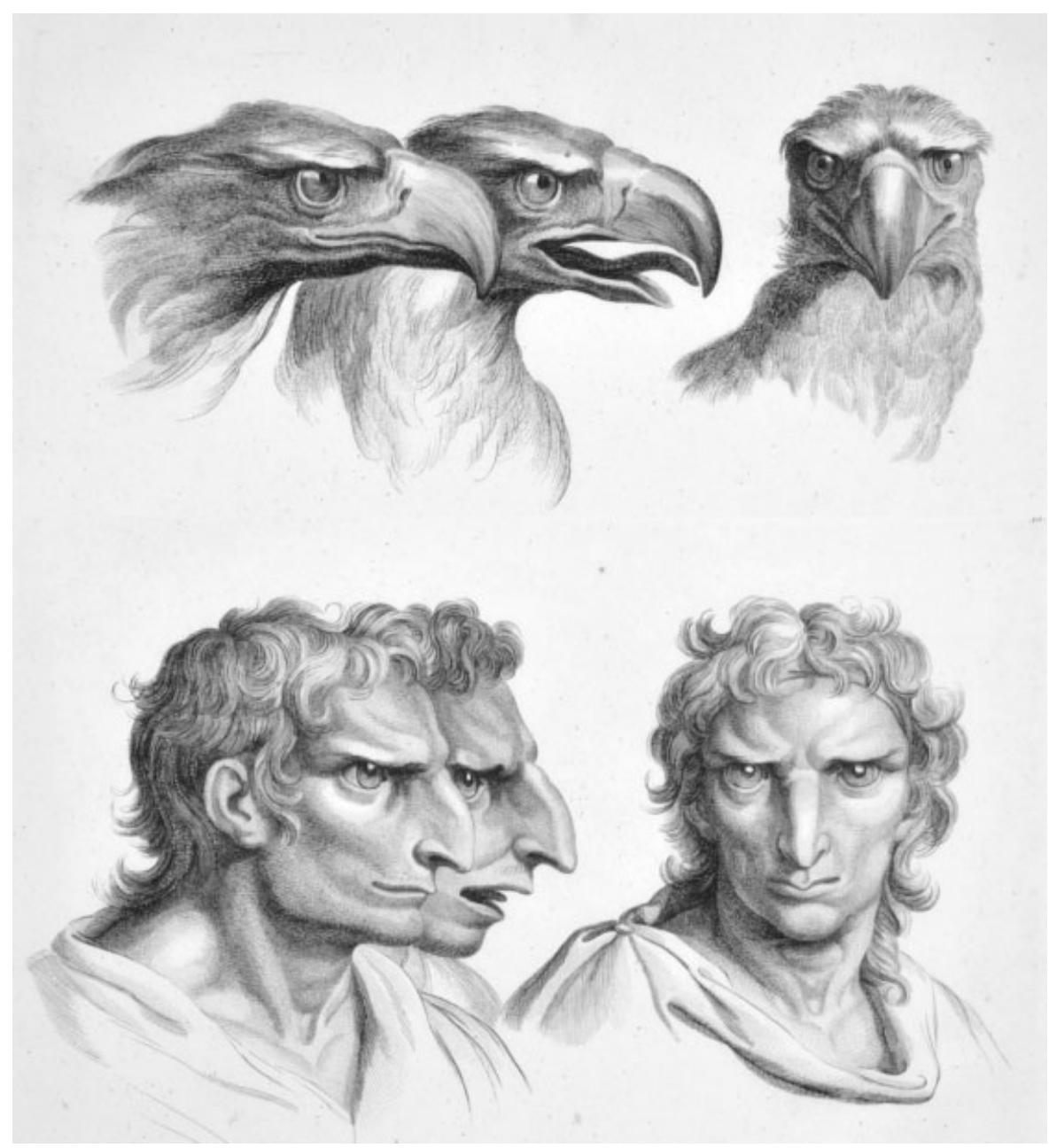

Fig. 6 Louis-Pierre Baltard (1764-1846). Human and eagle (by Charles Le Brun). ${ }^{17}$

prominence in da Vinci's portraits. ${ }^{18}$ The currently most common used measures for facial profile analysis are da Vinci's golden ratio dividing the face in thirds, the tip projection as the distance that the nasal tip projects from the face, the nasolabial, nasofrontal, nasofacial, and nasomental angle (-Fig. 8). Among all methods analyzing the relationship between nose and face, da Vinci's three thirds and Baud's facial circle belong to the most popular ones ( - Fig. 8). In 1966, Baud modified the method described by R. Goode to determine projection by using a "facial circle" to analyze nasal projection in relation to the sagittal projection of forehead and chin. ${ }^{19}$

\section{Ethnic Influences}

The influence of ethnic differences in the aesthetic judgment has been shown by many authors. Langlois and coworkers underline the cultural-specific standards of beauty and that faces least deviating from the normal cultural standard are the paragon of facial beauty. ${ }^{21}$ As a matter of fact, facial characteristics and the taste of beauty differ mostly in the area of the nose, the eye, the mouth, and the ear. The most prominent traits of the Asian face are the epicanthal fold and the under-projected dorsum of a small nose with flared nostrils. On the contrary, Caucasians present the so-called double eyelid contour with deeper-set eyes, higher or overprojected nose often and a rather elongated narrow facial shape. The typical African face may be characterized by its wide, under-projected nose, the thicker dark brown or black skin, and full upper and lower lips. ${ }^{22-24}$

Facing ancient profiles, many of the previously described traits may be recognized, each representing its own identity. So busts of the ancient race of the Copts as of Amenophis the second, also known as Younger Memnon (- Fig. 9), show facial features as a sloping forehead, full eyes stretching toward the temple, enlarged nostrils, elevated ear, and full lips which contrast interestingly with the later Greek and Roman facial profile and even to trends of the modern world.

When considering ethnical differences in the measurements of a facial profile, there are various investigations found in the current literature. Sheridan and colleagues used the Fourier shape analysis in the quantification of facial profiles of 121 healthy dental students and investigated the 

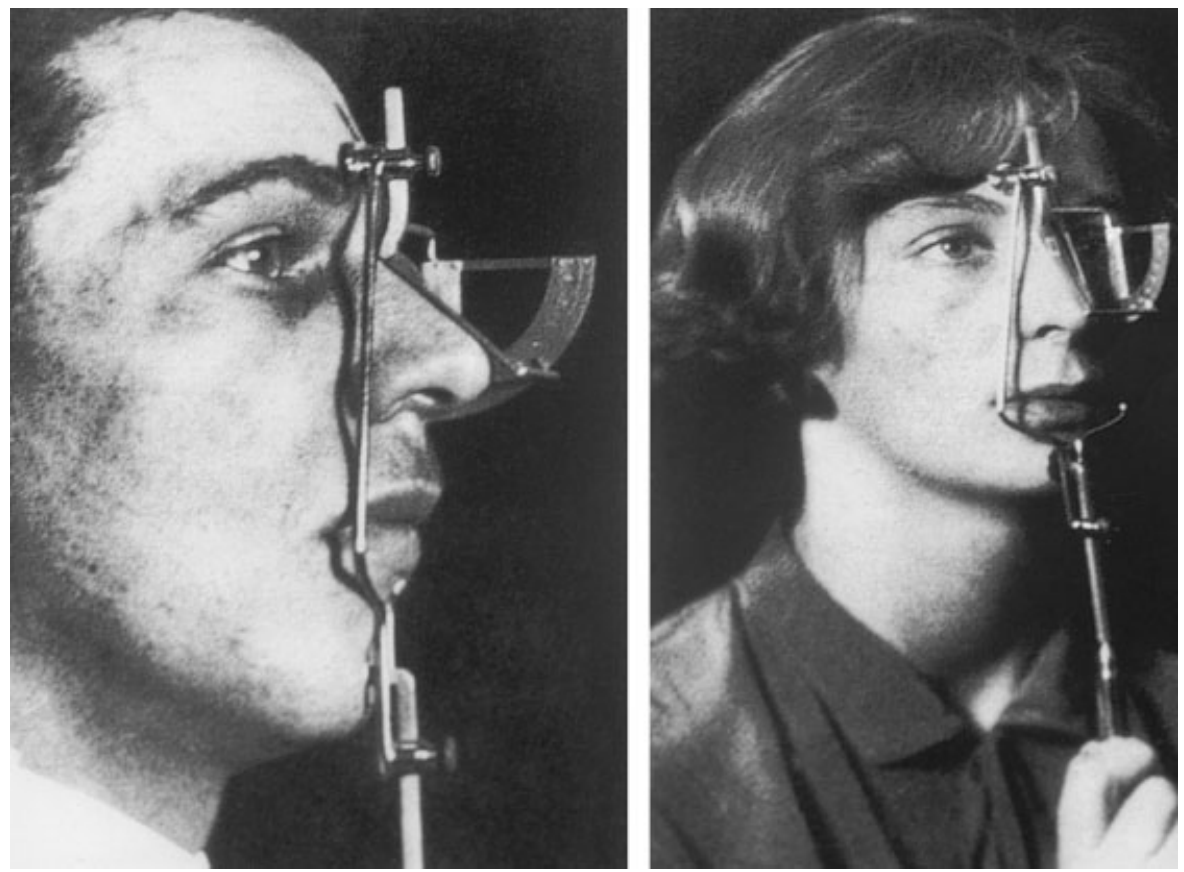

Fig. 7 Profilometer of Jacques Joseph. ${ }^{9}$

A
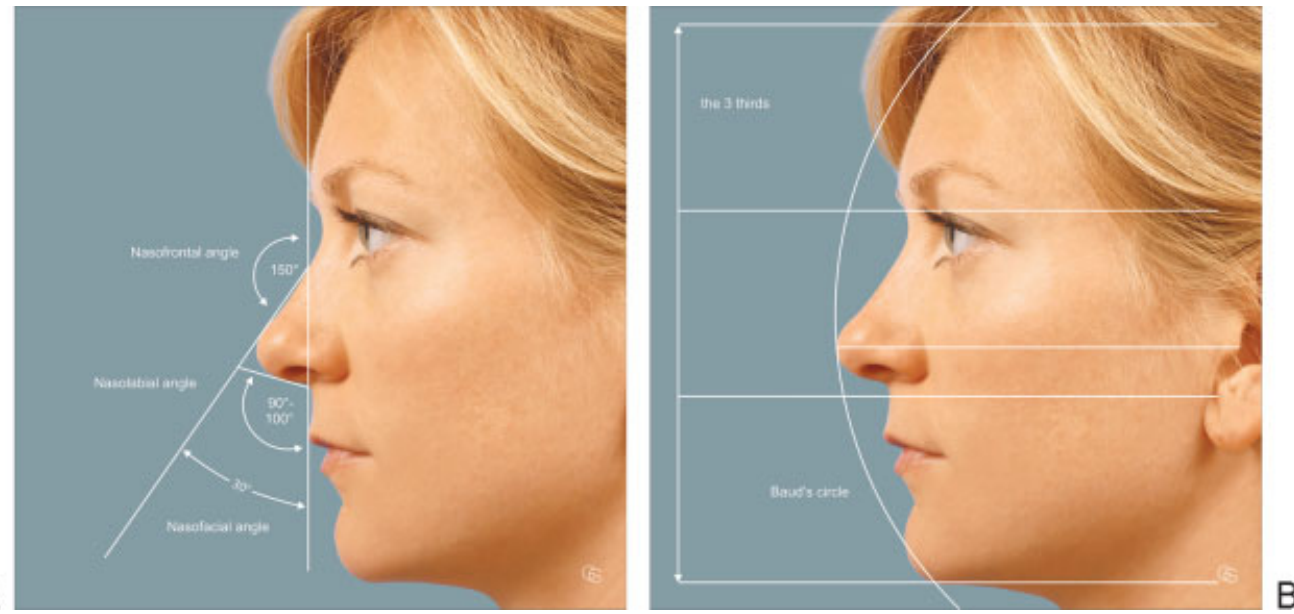

Fig. 8 Measurements of the facial profile. (A) Nasofrontal, nasolabial, and nasofacial angle. (B) The three thirds and Baud's circle. ${ }^{20}$

differences between racial groups. A comparison of multiple means tests revealed significant differences $(p<0.05)$ in the third-order Fourier harmonic (vertex projection) between the Asian group and the Anglo-Celtic, Eastern European, and Western European groups. Differences correlated with convexity in the lower third of the face, which was demonstrated by Fourier reconstruction. ${ }^{25}$

\section{Future Outlook: Current Facial Plastic Surgery}

Considering history, ethnics, gender, and age-related differences, there is no dogma in facial beauty nor in the ideal facial profile, which is supposed to give character to a face.
The aim of facial plastic surgery is to find and underline every person's beauty. It is not to obtain perfect symmetry, but merely to bring an abnormality within the range of normal limits for a specific type of individuality. The surgeon has to consider the patient's face and his or her wish, and then consult on feasible options when planning and conducting surgery. This is underlined by a recent study from the University of Regensburg investigating the three main hypotheses summing up beauty. ${ }^{26}$

1. Hypothesis of the average-a face appears attractive if its proportions approach a mathematical median of a population.

2. Hypothesis of symmetry-the more symmetric, the more attractive faces appear. 


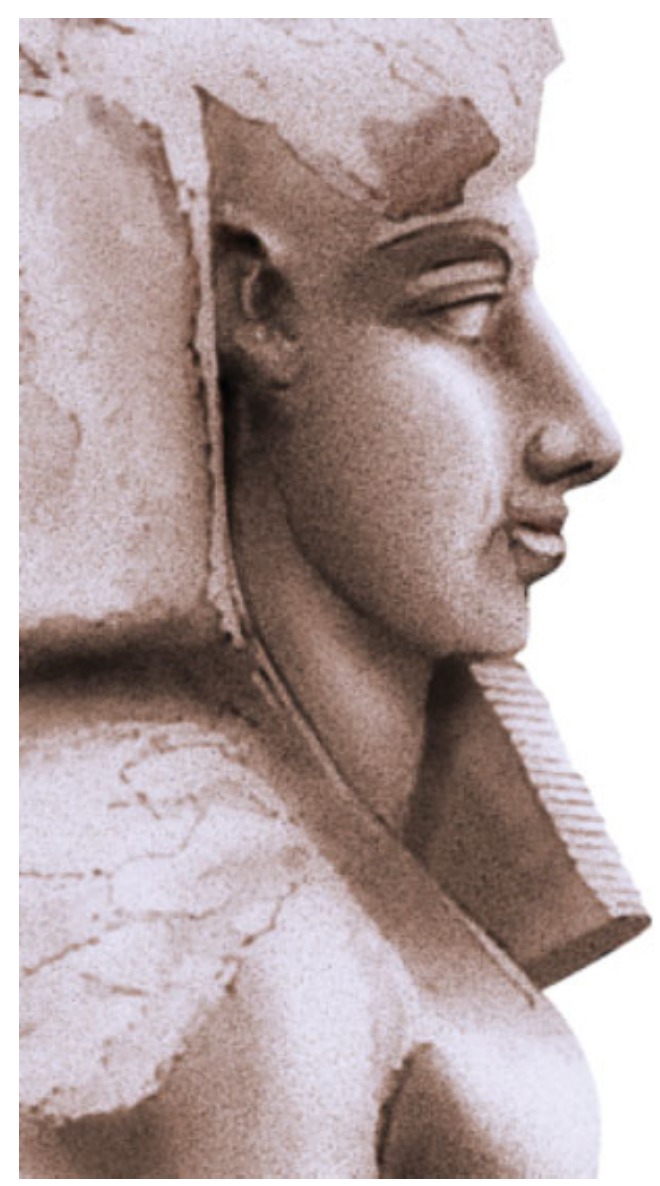

Fig. 9 Bust of Ramses II, called "The Younger Memnon," 19th Dynasty, $\sim 1250$ BCE.
3. Hypothesis of sexual dimorphism (female faces are rated more attractive, the more feminine they are, and male faces, the more masculine they are).

Analyzing different features, computer-morphed faces appeared more attractive, the more flawless the skin appeared, and not the more perfect the angles and measurements of the facial structures were. Thus, this important work questions all previous studies on attractiveness, and they also thoroughly analyzed previous studies, which often had methodological errors. Asymmetries to their finding were not seen as a major criterion for unattractiveness. ${ }^{26}$

Leong and White in 2006 also analyzed the common rules for an aesthetic ideal, and found that in 50 healthy Caucasians, the average nose did not conform to the neoclassical facial canons-concluding that we may have to rethink our guidelines when counseling patients regarding surgical options. ${ }^{19}$

The goal of the facial plastic surgeon is to find the way between general accepted and the individual beauty considering race, culture, gender, and age. Facial mimics and the individual personality are equally important as harmonious proportions between the different facial areas and other factors such as skin type, hair style, non-dynamic and mimic rhytids, and shape of the auricle. Even the role of the dental profile receives increased attention. Fortes and colleagues found that the anteroposterior position of the lower lip and the lip-chin proportion appeared to influence the rating of pleasantness of a facial profile, and Wang et al underlined in a larger Chinese group the role of jaw position determining facial convexity perceived as esthetic favorable..$^{27,28}$

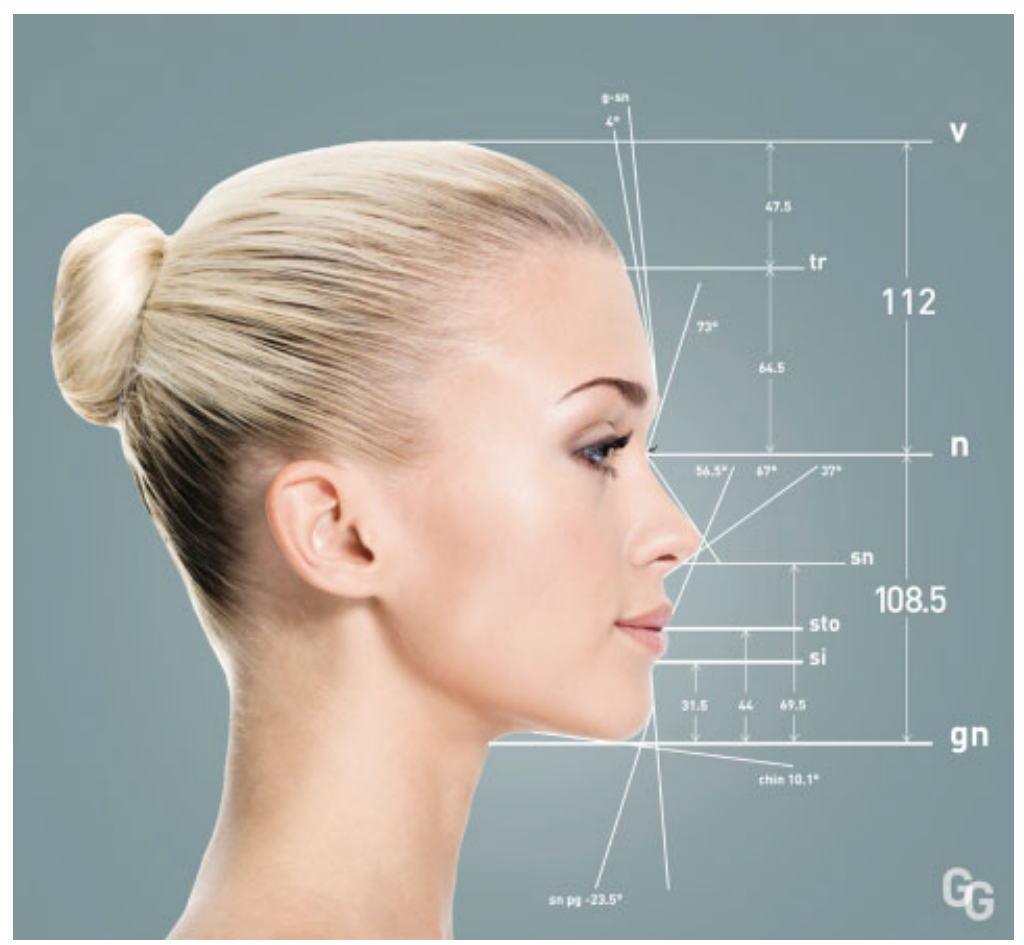

Fig. 10 Facial profile analysis. 
Extended knowledge about the so-called beauty zones and on the other hand about aging processes on a molecular basis calls for further improvement even in the field of facial rejuvenation. The antiaging concepts of lifting, filling, and paralyzing-defined areas need innovation integrating stem cells and various cell-modulating factors. ${ }^{29-31}$

In the time of global media and merging cultures, the contemporary beauty ideals will change more rapidly. This development will pose increased requirements to the facial plastic surgeon. Furthermore, in today's practices, two- and three-dimensional software programs to simulate the aging processes and possible surgical outcomes have been developed. They are now even setting modern standards and are no longer dispensable in patient consultation. Using angles, measure, and calculating points may be valuable in defining facial structures and analyzing pre- and postoperative findings (-Fig. 10). They are useful in comparing an individual case with the norm, but the facial plastic surgeon should be aware that finally it does not exist.

The concept of a beautiful optimum elaborated by da Vinci evolved to date to a desire to normalize beauty and make it accessible as an average value to everybody. If in the early days of facial plastic surgery, the primary indications for surgery were pathologically low self-esteem due to unpleasant appearance, we currently see a pathological urge for surgery due to a body dysmorphic disorder-which is a contraindication for surgery. ${ }^{10}$

\section{Conclusion}

The eternal search for physical perfection drew mankind to define beauty and set rules and criteria for an attractive body and a balanced facial profile. Although these rules change over times and cultures/ethnicity, the basis has been unchanged since da Vinci's elaboration of the Vitruvian man. It is likely that in art, subconsciously stricter rules are applied to perceive a perfect face than in reality, as clinical studies have shown. This has to be considered when consulting patients before facial plastic surgery. Nevertheless, owing to the myriad of factors influencing the outer appearance of a face, all attempts to set up golden standards of proportions will fail. The aim is neither the perfect Greek profile with a steep forehead forming a straight nasal line nor the Roman profile showing a slightly convex nasal dorsum, but a harmonious profile individualized to each patient.

\section{References}

1 Walker MJ, Gibert J, López MV, et al. Late Neandertals in southeastern Iberia: Sima de las Palomas del Cabezo Gordo, Murcia, Spain. Proc Natl Acad Sci U S A 2008;105(52):20631-20636

2 Rodríguez-Vidal J, d'Errico F, Giles Pacheco F, et al. A rock engraving made by Neanderthals in Gibraltar. Proc Natl Acad Sci U S A 2014; 111(37):13301-13306

3 Zilhão J, Angelucci DE, Badal-García E, et al. Symbolic use of marine shells and mineral pigments by Iberian Neandertals. Proc Natl Acad Sci U S A 2010;107(3):1023-1028
4 Tapsoba I, Arbault S, Walter P, Amatore C. Finding out Egyptian gods' secret using analytical chemistry: biomedical properties of Egyptian black makeup revealed by amperometry at single cells. Anal Chem 2010;82(2):457-460

5 Gay R. Proportion and Style in Ancient Egyptian Art, 1st ed. University of Texas Press; 1994:73-76

6 Lucas A. Cosmetics, perfumes and incense in ancient Egypt. J Egypt Archaeol 1930;16(1/2):41-53

7 "Mostra di Leonardo," Palazzo della cancelleria, Piazza della Cancelleria, 00186. Roma, Italy; Available at: http://www.mostradileonardo.com; Accessed September 1, 2015

8 "La Specola Museo - Collezione Ceroplastica," MUSEO DI STORIA NATURALE, Via Giorgio La Pira, 4, 50121 FIRENZE, Italy. Available at: http://www.msn.unifi.it/collezioni/ceroplastica-2/; Accessed September 1, 2015

9 Joseph J Über die operative Verkleinerung der Nase (Rhinomiot), Berliner Klinische Wochenschrift, 3 October 1898:881-886

10 Ramsbrock A. Korrigierte Körper - Eine Geschichte künstlicher Schönheit in der Moderne, 1st ed. Göttingen: Wallsteinverlag; 2011

11 Dürer A. Vier Bücher von menschlicher Proportion. Edited by Willibald Pirckheimer. Nuremberg: Hieronymus Andreae Formschneider for Dürer's widow, 31 October 1528

12 Brugger W. Philosophisches Wörterbuch, 9th ed. Freiburg: Herder; 2009:29f

13 Kania E. Die Grundzüge der mittelalterlichen Philosophie des Schönen bei Thomas von Aquin [master thesis Lehrstuhl Philosophie], RWTH Aachen, NRW Germany; 2001

14 Foerster R, ed. Scriptores physiognomonici graeci et Latini I-II, 1st ed, 2 books. Leipzig 1893, reprint Stuttgart/Leipzig; 1994

15 Danieul-Cormier A. Le speculum Physiognomiae de Michel Savonarole et ses sources in Positions des theses de l'Ecole nationale des chartes, Paris; 1953

16 della Porta G. Human and sheep. De Humana Physiognomia. 1586, 70132908: bpk/RMN-Grand Palais/Martine Beck-Coppola

17 Baltard L-P. Human and eagle. Album Charles Le Brun. 1789, 70132909: bpk/RMN-Grand Palais/image Beaux-arts de Paris

18 Farhad B, Naini B. Leonardo da Vinci's aesthetic analysis of nasal tip prominence. Arch Facial Plast Surg 2012;14(6): 463-464

19 Leong SC, White PS. A comparison of aesthetic proportions between the healthy Caucasian nose and the aesthetic ideal. J Plast Reconstr Aesthet Surg 2006;59(3):248-252

20 Koppe T, Giotakis EI, Heppt W. Functional anatomy of the nose. Facial Plast Surg 2011;27(2):135-145

21 Ritter JM, Casey RJ, Langlois JH. Adults' responses to infants varying in appearance of age and attractiveness. Child Dev 1991;62(1): 68-82

22 Behrbohm H, Tardy M Jr. Funktionell-aestehtische Chirurgie der Nase. Stuttgart: Thieme Verlag; 2004

23 Ofodile FA, Bokhari F. The African-American nose: Part II. Ann Plast Surg 1995;34(2):123-129

24 Porter JP, Olson KL. Analysis of the African American female nose. Plast Reconstr Surg 2003;111(2):620-626, discussion 627-628

25 Sheridan CS, Thomas CD, Clement JG. Quantification of ethnic differences in facial profile. Aust Orthod J 1997;14(4): 218-224

26 Gründl M. “Determinanten Physischer Attraktivität," PhD dissertation, University of Regensburg, Germany. Available Online at: http://epub.uni-regensburg.de/27663/

27 Fortes HN, Guimarães TC, Belo IM, da Matta EN. Photometric analysis of esthetically pleasant and unpleasant facial profile. Dental Press J Orthod 2014;19(2):66-75

28 Wang YY, Guo CC, Zhou C, Fan ML, Wang WC, Bao BC. Investigation on facial profile preferences of orthodontic patients [in Chinese]. Shanghai Kou Qiang Yi Xue 2012;21(6):668-672 
430 Facial Profile in the Context of Facial Aesthetics Heppt, Vent

29 Fitzgerald $\mathrm{R}$, Graivier $\mathrm{MH}$, Kane $\mathrm{M}$, et al. Update on facial aging. Aesthet Surg J 2010;30(Suppl):11S-24S

30 Carruthers JD, Glogau RG, Blitzer A; Facial Aesthetics Consensus Group Faculty. Advances in facial rejuvenation: botulinum toxin type a, hyaluronic acid dermal fillers, and combination therapies- consensus recommendations. Plast Reconstr Surg 2008;121(5, Suppl):5S-30S, quiz 31S-36S

31 Kane M, Donofrio L, Ascher B, et al. Expanding the use of neurotoxins in facial aesthetics: a consensus panel's assessment and recommendations. J Drugs Dermatol 2010;9(1, Suppl):s7-s22, quiz s23-s25 